\title{
Survival and Heart Failure Hospitalization in Patients With Cardiac Resynchronization Therapy With or Without a Defibrillator for Primary Prevention in Japan
}

\author{
- Analysis of the Japan Cardiac Device \\ Treatment Registry Database -
}

\begin{abstract}
Hisashi Yokoshiki, MD, PhD; Akihiko Shimizu, MD, PhD; Takeshi Mitsuhashi, MD, PhD; Hiroshi Furushima, MD, PhD; Yukio Sekiguchi, MD, PhD; Tetsuyuki Manaka, MD, PhD; Nobuhiro Nishii, MD, PhD; Takeshi Ueyama, MD, PhD; Norishige Morita, MD, PhD; Hideo Okamura, MD, PhD; Takashi Nitta, MD, PhD; Kenzo Hirao, MD, PhD; Ken Okumura, MD, PhD for the Members of the Implantable Cardioverter-Defibrillator (ICD) Committee of the Japanese Heart Rhythm Society
\end{abstract}

Background: Randomized control trials comparing the effectiveness of cardiac resynchronization therapy devices, with (CRT-D) or without (CRT-P) a defibrillator, are scarce in heart failure patients with no prior sustained ventricular tachyarrhythmias.

Methods and Results: The Japan Cardiac Device Treatment Registry (JCDTR) has data for 2714 CRT-D and 555 CRT-P recipients for primary prevention with an implantation date between January 2011 and August 2015. Of these patients, follow-up data were available for 717. Over the mean follow-up period of 21 months, Kaplan-Meier curves of survival free of combined events for all-cause death or heart failure hospitalization (whichever came first) diverged between the CRT-D ( $n=620)$ and CRT-P ( $n=97)$ groups with a rate of $22 \%$ vs. $42 \%$, respectively, at 24 months $(P=0.0011)$. However, this apparent benefit of CRT-D over CRT-P was no longer significant after adjustment for covariates. With regard to mortality, including heart failure death or sudden cardiac death, there was no significant difference between the 2 groups.

Conclusions: In patients without sustained ventricular tachyarrhythmias enrolled in the JCDTR, there was no significant difference in mortality between the CRT-D and CRT-P groups, despite a lower trend in CRT-D recipients. This study was limited by large clinical and demographic differences between the 2 groups.

Key Words: Cardiac resynchronization therapy (CRT); CRT defibrillator (CRT-D); CRT pacemaker (CRT-P); Primary prevention

$\mathbf{C}$ ardiac resynchronization therapy (CRT) using an atrial-synchronized biventricular pacemaker (CRT-P) has been the established treatment for patients with symptomatic heart failure, left ventricular ejection fraction (LVEF) $\leq 35 \%$, and a QRS duration $\geq 130 \mathrm{~ms}$ since the Multicenter InSync Randomized Clinical

\section{Editorial p1768}

Evaluation (MIRACLE) study was reported in 2002. ${ }^{1}$ The Comparison of Medical Therapy, Pacing, and Defibrillation in Heart Failure (COMPANION) study proved a better

Received March 2, 2017; revised manuscript received May 11, 2017; accepted May 15, 2017; released online June 13, 2017 Time for primary review: 32 days

Department of Cardiovascular Medicine, Hokkaido University Graduate School of Medicine, Sapporo (H.Y.); Faculty of Health Sciences (A.S.), Division of Cardiology, Department of Medicine and Clinical Sciences (T.U.), Yamaguchi Graduate School of Medicine, Ube; Cardiovascular Medicine, Jichi Medical University Saitama Medical Center, Saitama (T. Mitsuhashi); Furushima Clinic, Niigata (H.F.); Cardiovascular Division, Faculty of Medicine, University of Tsukuba, Tsukuba (Y.S.); Asakusa Heart Clinic, Tokyo (T. Manaka); Department of Cardiovascular Medicine, Okayama University Graduate School of Medicine, Dentistry, and Pharmaceutical Sciences, Okayama (N.N.); Division of Cardiology, Department of Medicine, Tokai University Hachioji Hospital, Hachioji (N.M.); Department of Cardiovascular Medicine, National Cerebral and Cardiovascular Center, Suita (H.O.); Department of Cardiovascular Surgery, Nippon Medical School, Tokyo (T.N.); Heart Rhythm Center, Tokyo Medical and Dental University, Tokyo (K.H.); and Cardiovascular Center, Saiseikai Kumamoto Hospital, Kumamoto (K.O.), Japan

Mailing address: Hisashi Yokoshiki, MD, PhD, Department of Cardiovascular Medicine, Hokkaido University Graduate School of Medicine, Kita-15, Nishi-7, Kita-ku, Sapporo 060-8638, Japan. E-mail: yokoshh@med.hokudai.ac.jp

ISSN-1346-9843 All rights are reserved to the Japanese Circulation Society. For permissions, please e-mail: cj@j-circ.or.jp 


\begin{tabular}{|c|c|c|c|}
\hline & $\begin{array}{c}\text { CRT-D } \\
(n=620)\end{array}$ & $\begin{array}{l}\text { CRT-P } \\
(n=97)\end{array}$ & $P$ value \\
\hline Age (years) & $66.8 \pm 11.2$ & $77.0 \pm 10.2$ & $<0.0001$ \\
\hline Male & $476(76.8)$ & $59(60.8)$ & 0.0008 \\
\hline Underlying heart disease & & & 0.197 \\
\hline Ischemic & $173(27.9)$ & $21(21.6)$ & \\
\hline Non-ischemic & $447(72.1)$ & $76(78.4)$ & \\
\hline LVEF (\%) & $26.5 \pm 9.0$ & $33.0 \pm 11.1$ & $<0.0001$ \\
\hline LVEF $\leq 35 \%$ & $553(89.2)$ & $68(70.1)$ & $<0.0001$ \\
\hline NYHA class & & & 0.803 \\
\hline 1 & $8(1.3)$ & $2(2.1)$ & \\
\hline II & $165(26.6)$ & $22(22.7)$ & \\
\hline III & $383(61.8)$ & $63(64.9)$ & \\
\hline IV & $64(10.3)$ & $10(10.3)$ & \\
\hline Heart rate (beats/min) & $71.1 \pm 17.2$ & $74.0 \pm 19.1$ & 0.134 \\
\hline QRS duration (ms) & $153.5 \pm 30.7$ & $157.9 \pm 24.7$ & 0.172 \\
\hline QRS duration (ms) class & & & 0.023 \\
\hline$<120$ & $76(12.3)$ & $3(3.1)$ & \\
\hline $120-149$ & $203(32.7)$ & $32(33.0)$ & \\
\hline$\geq 150$ & $341(55.0)$ & $62(63.9)$ & \\
\hline QT interval (ms) & $455.3 \pm 55.4$ & $463.2 \pm 48.3$ & 0.185 \\
\hline Atrial lead & & & 0.672 \\
\hline Absent & $92(14.8)$ & $16(16.5)$ & \\
\hline Present & $528(85.2)$ & $81(83.5)$ & \\
\hline NSVTA & $179(66.5)^{\mathrm{A}}$ & $4(26.7)^{A}$ & 0.0017 \\
\hline AF & $82(13.2)$ & $12(12.4)$ & 0.817 \\
\hline Type of AF & & & 0.705 \\
\hline Paroxysmal/persistent & $32(39) / 50(61)$ & $4(33) / 8(67)$ & \\
\hline Diabetes mellitus & $195(31.5)$ & $28(28.9)$ & 0.609 \\
\hline Hypertension & $242(39.0)$ & $53(54.6)$ & 0.0037 \\
\hline Dyslipidemia & $186(30.0)$ & $28(28.9)$ & 0.820 \\
\hline Hyperuricemia & $127(20.5)$ & $17(17.5)$ & 0.499 \\
\hline Cerebral infarction & $44(7.1)$ & $6(6.2)$ & 0.743 \\
\hline Peripheral artery disease & $19(3.1)$ & $4(4.1)$ & 0.582 \\
\hline $\mathrm{BNP}(\mathrm{pg} / \mathrm{mL})^{\mathrm{B}}$ & $781.0 \pm 1,324.8$ & $820.1 \pm 822.1$ & 0.799 \\
\hline Hemoglobin (g/dL) & $12.7 \pm 2.1$ & $12.2 \pm 1.9$ & 0.0243 \\
\hline Creatinine $(\mathrm{mg} / \mathrm{dL})$ & $1.48 \pm 1.48$ & $1.45 \pm 1.60$ & 0.858 \\
\hline Goldenberg score ${ }^{c}$ & $2.3 \pm 1.1$ & $2.7 \pm 0.9$ & 0.0008 \\
\hline
\end{tabular}

Data are presented as the mean $\pm \mathrm{SD}$ or as $\mathrm{n}(\%)$. Alnformation regarding the presence or absence of non-sustained ventricular tachycardia (NSVT) was available in 269 patients implanted with a cardiac resynchronization therapy defibrillator (CRT-D) and 15 patients implanted with a cardiac resynchronization therapy pacemaker (CRT-P). BB-Type natriuretic peptide (BNP) data were missing for 67 CRT-D recipients and 18 CRT-P recipients. CThe original risk score model comprised 5 clinical factors, namely New York Heart Association (NYHA) Class $>$ II, atrial fibrillation (AF), QRS duration $>120 \mathrm{~ms}$, age $>70$ years, and blood urea nitrogen $(\mathrm{BUN})>26 \mathrm{mg} / \mathrm{dL}$. Because BUN data were not collected in the Japan Cardiac Device Treatment Registry (JCDTR) database, blood creatinine $>1.5 \mathrm{mg} / \mathrm{dL}$ was used as a risk factor instead of BUN. Data on all 5 factors were available for 609 CRT-D recipients and 95 CRT-P recipients. LVEF, left ventricular ejection fraction.

prognosis of moderate-to-severe heart failure (New York Heart Association (NYHA) Class III or IV) patients using CRT compared with optimal pharmacologic therapy alone, especially when an implantable cardioverter-defibrillator (ICD) backup was present (CRT-D). ${ }^{2}$ In addition, CRT-P was shown to reduce the risk of death in advanced heart failure patients and in patients with cardiac dyssynchrony due to a prolonged QRS interval of at least $120 \mathrm{~ms}$ in the Cardiac Resynchronization-Heart Failure (CARE-HF) study. ${ }^{3}$ However, randomized controlled trials directly comparing the efficacy of CRT-D with that of CRT-P are extremely scarce., ${ }^{2,4,5}$
In the COMPANION study, CRT-P decreased the risk of the primary composite endpoint of death from or hospitalization for any cause, as did CRT-D. ${ }^{2}$ With regard to mortality, CRT-D appeared to be superior to CRT-P, but a direct comparison between 2 devices was not performed. ${ }^{2}$ In the extended follow-up observation of patients enrolled for the REsynchronization reVErses Remodeling in Systolic left vEntricular dysfunction (REVERSE) study ${ }^{4}$ compared with CRT-P, CRT-D significantly decreased the risk of death in patients with asymptomatic-to-mild heart failure (NYHA Class I or II) who had an LVEF of $\leq 40 \%$ and a QRS interval of $\geq 120 \mathrm{~ms}$ more. ${ }^{4}$ In contrast, advanced 


\begin{tabular}{|lcll|}
\hline Table 2. Pharmacological Therapy & & & \\
& $\begin{array}{c}\text { CRT-D } \\
(\mathbf{n = 6 2 0})\end{array}$ & $\begin{array}{c}\text { CRT-P } \\
(\mathbf{n}=\mathbf{9 7})\end{array}$ & P value \\
Antiarrhythmic drugs & & & \\
$\quad$ Class la & $5(0.8)$ & $2(2.1)$ & 0.242 \\
Class Ib & $14(2.3)$ & $2(2.1)$ & 0.903 \\
Class Ic & $5(0.8)$ & $2(2.1)$ & 0.242 \\
Class III & $199(32.1)$ & $18(18.6)$ & 0.0069 \\
$\beta$-blockers & $477(76.9)$ & $60(61.9)$ & 0.0014 \\
Ca'+ antagonists & $53(8.5)$ & $13(13.4)$ & 0.124 \\
Digitalis & $83(13.4)$ & $17(17.5)$ & 0.274 \\
Diuretics & $499(80.5)$ & $74(76.3)$ & 0.338 \\
ACEl or ARB & $413(66.6)$ & $55(56.7)$ & 0.0566 \\
Aldosterone antagonists & $277(44.7)$ & $29(29.9)$ & 0.0062 \\
Nitrates & $73(11.8)$ & $13(13.4)$ & 0.646 \\
Statins & $192(31.0)$ & $22(22.7)$ & 0.0972 \\
Oral anticoagulant agents & $325(52.4)$ & $44(45.4)$ & 0.196 \\
Antiplatelet agents & $241(38.9)$ & $28(28.9)$ & 0.0584 \\
\hline
\end{tabular}

Data are given as $\mathrm{n}(\%)$. ACEI, angiotensin-converting enzyme inhibitor; ARB, angiotensin-receptor blocker. Other abbreviations as in Table 1.

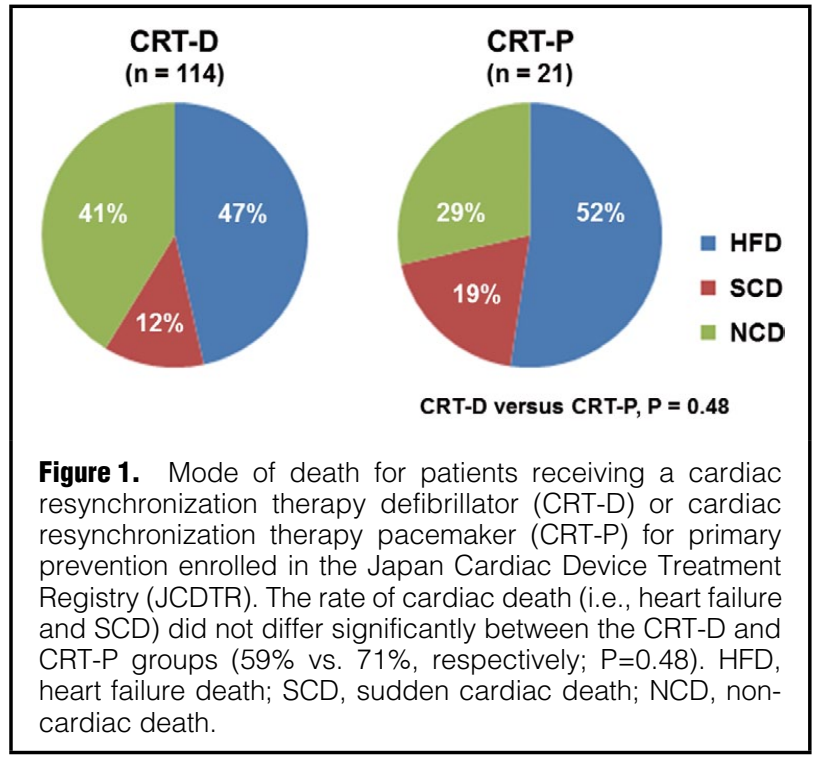

heart failure patients enrolled in the Management of Atrial fibrillation Suppression in AF-HF COmorbidity Therapy (MOSCOT) study showed similar survival rates with CRT-D vs. CRT-P during the 12-month follow-up period. ${ }^{5}$ Together, these studies indicate that there are likely to be small differences, if any, between heart failure patients with no prior sustained ventricular tachyarrhythmias (i.e., primary prevention) receiving CRT-D and CRT-P with regard to mortality or the rate of hospitalization for heart failure.

The aim of the present study was to clarify the effect of CRT-D and CRT-P for primary prevention on morbidity and mortality in patients with heart failure based on data from the Japan Cardiac Device Treatment Registry (JCDTR).

\section{Study Population}

The JCDTR was established in 2006 by the Japanese Heart Rhythm Society (JHRS) for a survey of actual conditions in patients undergoing implantation of cardiac implantable electronic devices (ICD, CRT-D, CRT-P), as described previously. ${ }^{68}$ This database is maintained on a voluntary basis by members of the JHRS under a unified protocol (https://center6.umin.ac.jp/islet/icd/plan_ verion_1_20090730.pdf), which is normally approved by each participating facility. As of 13 January 2017, 378 medical facilities in Japan had registered their data with the JCDTR. All members are encouraged to submit patient data at the time of implantation, as well as events related mortality and ICD therapy during the follow-up period, via the web page using a University hospital Medical Information Network (UMIN) server (https://center6. umin.ac.jp/islet/icd/index.htm). Details regarding data at the time of implantation have been reported previously. ${ }^{9}$ Of all patients receiving devices for primary prevention (2714 CRT-D, 555 CRT-P) with an implantation date between January 2011 and August 2015, follow-up data were available for 717 patients (620 CRT-D, 97 CRT-P) as of 16 September 2015. These 717 patients were included in the present study.

\section{Outcomes}

The events analyzed were in the present study: (1) death from any cause; (2) death from any cause or heart failure hospitalization, whichever came first; (3) heart failure death; and (4) sudden cardiac death. Diagnoses of heart failure were made and causes of death were ascertained by attending physicians.

\section{Statistical Analyses}

All data are expressed as the mean \pm SD. Simple betweengroup analyses were conducted using Student's t-tests. Categorical variables were compared using Fisher's exact test. Logistic regression analysis was used to estimate the factors affecting the choice of CRT-D vs. CRT-P. 

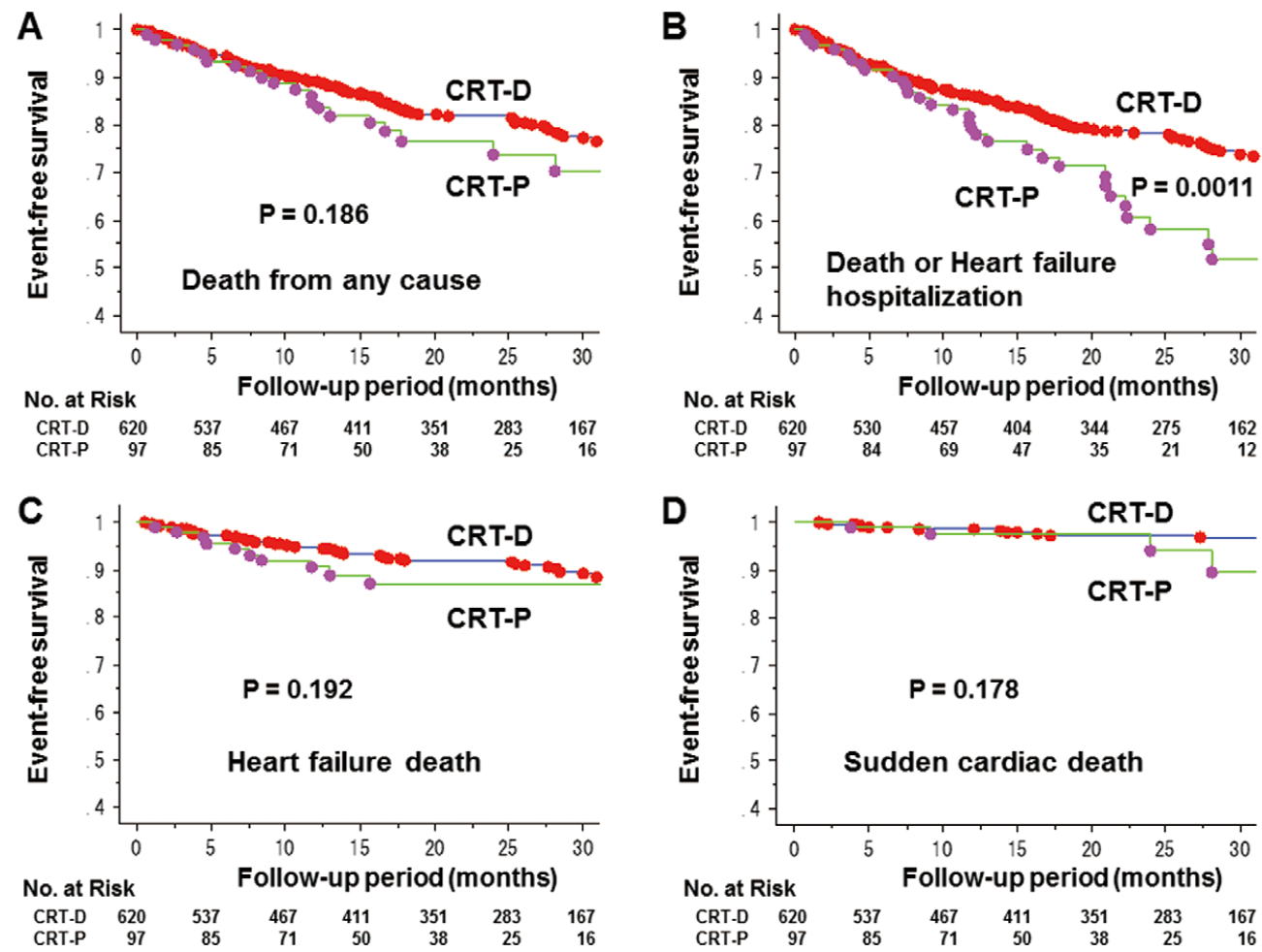

Figure 2. Kaplan-Meier estimates for event-free survival in patients with no prior sustained ventricular tachyarrhythmias and receiving a CRT-D or CRT-P. Outcome events were $(\mathbf{A})$ death from any cause, $(\mathbf{B})$ death or heart failure hospitalization (whichever came first), (C) heart failure death, and (D) SCD. (A) The rate of death from any cause at 12 and 24 months was $11 \%$ and $18 \%$, respectively, in the CRT-D group, compared with $15 \%$ and $26 \%$ in the CRT-P group ( $P=0.186$, log-rank test). (B) The rate of death or heart failure hospitalization at 12 and 24 months was $14 \%$ and $22 \%$, respectively, in the CRT-D group, compared with $21 \%$ and $42 \%$ in the CRT-P group ( $P=0.001)$. (C) The rate of heart failure death at 12 and 24 months was $5 \%$ and $8 \%$, respectively, in the CRT-D group, compared with 9\% and 13\% in the CRT-P group ( $P=0.193$ ). (D) The rate of SCD at 12 and 24 months was $1.3 \%$ and $2.7 \%$, respectively, in the CRT-D group, compared with $2.4 \%$ and $5.6 \%$ in the CRT-P group ( $P=0.178)$. Abbreviations as in Figure 1 .

Kaplan-Meier curves were constructed to estimate eventfree outcomes in the 2 study groups with comparisons using the log-rank test. Cox proportional-hazards regression model was used to estimate hazard ratios for clinical events. All covariates that reached a significance level of $\mathrm{P}<0.1$ were then included in a multivariate regression model. To minimize the indication bias for device implantation, propensity score analyses were also conducted. The propensity score was calculated with the Cox proportionalhazards regression model using the following variables: age; sex; etiology (ischemic vs. non-ischemic); NYHA class; LVEF; QRS duration; history of atrial fibrillation (AF) and hypertension; hemoglobin; and treatment with $\beta$-blockers, angiotensin-converting enzyme inhibitors (ACEI) or angiotensin receptor blockers (ARB), aldosterone antagonists, and Class III anti-arrhythmic drugs. Two-sided $\mathrm{P}<0.05$ was considered significant. Statistical analyses were performed using Statview version 5.0 for Windows (SAS Institute, Cary, NC, USA) or R software ver.3.2.3 (https://www.r-project.org/).

\section{Results}

Patient Characteristics

The characteristics of patients receiving CRT-D $(n=620)$ and CRT-P $(n=97)$ devices for primary prevention are given in Table 1. Age and LVEF were significantly lower in the CRT-D than CRT-P group. Although a previous study reported significant prolongation of QRS duration in CRT-P recipients, ${ }^{9}$ there was no significant difference in QRS duration between the CRT-D than CRT-P groups in the present study. Male sex was prevalent in both groups, but its predominance was higher in patients with CRT-D. Patients receiving CRT-D were more likely to have a history of non-sustained ventricular tachycardia (NSVT). In contrast, they were less likely to have a history of hypertension. The distribution of NYHA functional classes and underlying heart diseases (ischemic vs. non-ischemic) did not differ significantly between the 2 groups, despite a trend for increased ischemic etiology in the CRT-D group. The Goldenberg risk score ${ }^{10}$ was lower in the CRT-D than CRT-P group.

Pharmacological therapy in the CRT-D and CRT-P groups is detailed in Table 2. The use of $\beta$-blockers, Class III anti-arrhythmic drugs, and aldosterone antagonists was significantly higher in the CRT-D group. There was a trend for higher use of ACEI or ARB and oral anticoagulant agents in the CRT-D than CRT-P group.

Among the clinical variables listed in Table 1, univariate logistic regression analyses identified 6 factors that were 


\begin{tabular}{|c|c|c|c|}
\hline Event & Hazard ratio & $95 \% \mathrm{Cl}$ & $P$ value \\
\hline \multicolumn{4}{|l|}{ Death from any cause } \\
\hline Unadjusted analysis & 0.73 & $0.46-1.17$ & 0.188 \\
\hline Adjusted analysis & 0.97 & $0.59-1.60$ & 0.897 \\
\hline \multicolumn{4}{|c|}{ Death or heart failure hospitalization } \\
\hline Unadjusted analysis & 0.54 & $0.37-0.78$ & 0.0014 \\
\hline Adjusted analysis & 0.72 & $0.47-1.10$ & 0.125 \\
\hline \multicolumn{4}{|l|}{ Heart failure death } \\
\hline Unadjusted analysis & 0.65 & $0.34-1.25$ & 0.196 \\
\hline Adjusted analysis & 0.67 & $0.33-1.37$ & 0.267 \\
\hline \multicolumn{4}{|l|}{ Sudden cardiac death } \\
\hline Unadjusted analysis & 0.47 & $0.16-1.44$ & 0.188 \\
\hline Adjusted analysis & 0.50 & $0.15-1.68$ & 0.259 \\
\hline
\end{tabular}

Models were adjusted for the following covariates: age at enrollment; underlying heart disease (ischemic vs. nonischemic); NYHA class; hemoglobin; history of hypertension; and the use of Class III anti-arrhythmic drugs and ACEIs and/or ARBs. Covariates were identified from univariate Cox regression analyses $(P<0.1)$. Cl, confidence interval. Other abbreviations as in Tables 1,2.

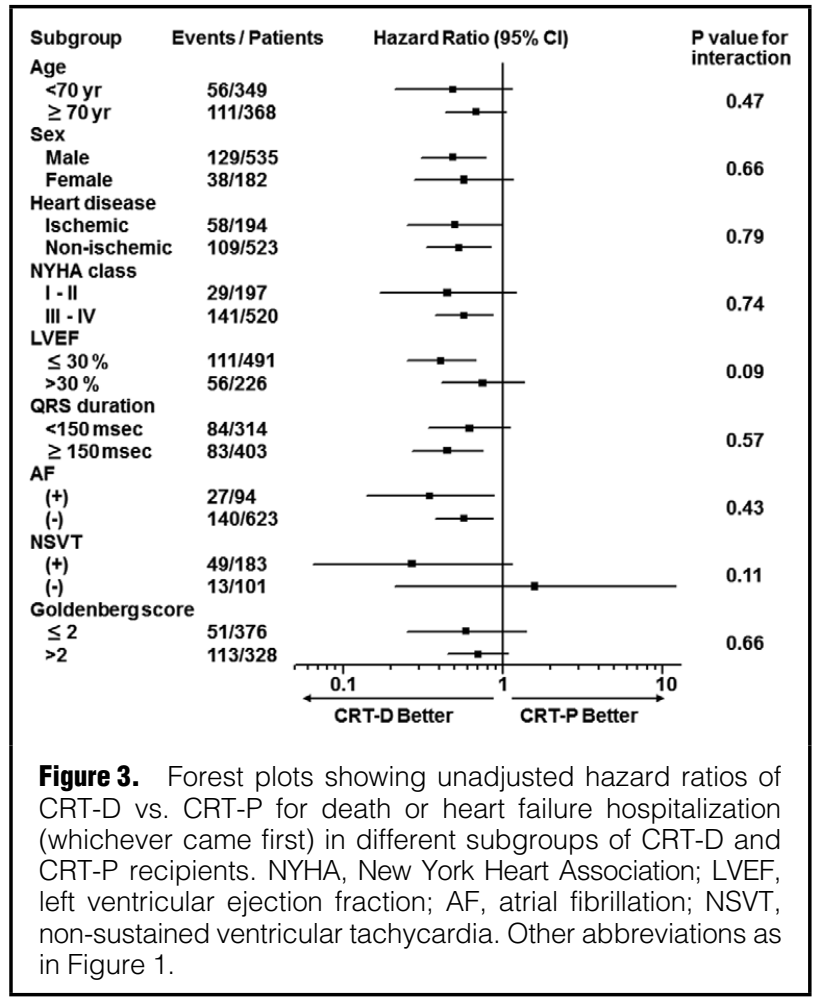

associated with CRT-D vs. CRT-P implantation, namely age $(\mathrm{P}<0.0001)$, sex $(\mathrm{P}=0.001)$, LVEF $(\mathrm{P}<0.0001)$, hemoglobin $(\mathrm{P}=0.025)$, and a history of hypertension $(\mathrm{P}=0.0041)$ and NSVT $(\mathrm{P}=0.0045)$. In the multivariate analysis, age (odds ratio [OR] $0.91,95 \%$ confidence interval [CI] 0.85 $0.98 ; \mathrm{P}=0.012$ ) and a history of NSVT (OR 5.38, 95\% CI $1.54-18.87 ; \mathrm{P}=0.0085)$ were independent variables associated with the choice of CRT-D vs. CRT-P.

\section{Outcomes}

Over a mean follow-up of $21 \pm 12$ months, death or heart failure hospitalization occurred in 134 of 620 patients $(21.6 \%)$ in the CRT-D group and in 33 of 97 patients
$(34.0 \%)$ in the CRT-P group. In this group, death from any cause occurred in 114 CRT-D patients $(18.4 \%)$ and in 21 CRT-P patients $(21.6 \%)$. These events included 53 heart failure deaths $(8.5 \%)$ and 14 sudden cardiac deaths $(2.3 \%)$ in the CRT-D group and 11 heart failure deaths $(11.3 \%)$ and 4 sudden cardiac deaths $(4.1 \%)$ in the CRT-P group. The mode of death did not differ between the 2 groups $(\mathrm{P}=0.48$; Figure 1). The incidence of cardiac death (i.e., heart failure and sudden cardiac death) was $59 \%$ in the CRT-D group and $71 \%$ in the CRT-P group.

The characteristics of the 4 patients with sudden cardiac death in the CRT-P group are summarized in Table S1. The rate of use of guideline-determined medical therapy, including $\beta$-blockers, ACEI/ARB, and aldosterone antagonists, was low in these patients. However, none of them had a history of hospital admission for heart failure after CRT-P implantation. Among the 14 CRT-D sudden cardiac deaths, 4 patients (29\%) had prior appropriate ICD therapy. The appropriate ICD therapy and sudden death occurred on the same day in 2 patients. In the remaining 2 patients, sudden death occurred within 2 months of the appropriate ICD therapy in the absence of heart failure hospitalization.

Kaplan-Meier estimates of event-free survival in the 2 groups are shown in Figure 2. With regard to death or heart failure hospitalization (Figure 2B), the curves diverge at approximately 12 months and continue to separate thereafter $(\mathrm{P}=0.0011)$.

Hazard ratios for death from any cause, death or heart failure hospitalization, heart failure death, and sudden cardiac death are presented in Table 3. The unadjusted hazard ratio of 0.54 would indicate that there was a $46 \%$ reduction in the risk of death or heart failure hospitalization (whichever came first) among patients in the CRT-D group compared with those in the CRT-P group. However, there was no significant difference between the 2 groups with regard to the events mentioned above after adjustment for covariates. Conversely, the adjusted hazard ratio for heart failure hospitalization was $0.41(95 \%$ CI $0.19-0.89 ; \mathrm{P}=0.024)$ in the CRT-D group compared with the CRT-P group.

Forest plots of unadjusted hazard ratios of CRT-D vs. CRT-P for death or heart failure hospitalization by different subgroups are shown in Figure 3. Two marginal inter- 


\begin{tabular}{|c|c|c|c|}
\hline Event & Hazard ratio & $95 \% \mathrm{Cl}$ & $P$ value \\
\hline Death from any cause & 0.58 & $0.23-1.48$ & 0.257 \\
\hline Death or heart failure hospitalization & 0.63 & $0.28-1.38$ & 0.244 \\
\hline Heart failure death & 0.38 & $0.10-1.41$ & 0.147 \\
\hline Sudden cardiac death ${ }^{A}$ & NA & NA & NA \\
\hline
\end{tabular}

ASudden cardiac death occurred in 3 of 166 patients within the propensity-matched cohort. All of these patients were recipients of a CRT-P, and so statistical analyses were not applicable. NA, not applicable. Other abbreviations as in Tables 1-3.

action effects, albeit lacking statistical significance, between subgroup and treatment were identified: (1) CRT-D was associated with a greater benefit in patients with LVEF $\leq 30 \%$ (hazard ratio $0.41 ; 95 \%$ CI $0.25-0.68$ ) than in those with LVEF $>30 \%$ (hazard ratio 0.75 ; 95\% CI 0.41-1.37; Pinteraction=0.090); and (2) CRT-D was associated with a greater benefit in patients with NSVT (hazard ratio 0.27 ; 95\% CI $0.065-1.15$ ) than in those without NSVT (hazard ratio $1.58 ; 95 \%$ CI $0.21-12.15$; $P_{\text {interaction }}=0.11$ ).

After propensity score matching, the study cohorts consisted of 83 CRT-D vs. 83 CRT-P patients (Table S2). Hazard ratios for all events with CRT-D vs. CRT-P tended to be lower, but they did not reach statistical significance (Table 4).

\section{Discussion}

In the present study, analysis of the JCDTR database demonstrated that heart failure patients receiving CRT-D had better outcomes in terms of a lower incidence of combined events of death or heart failure hospitalization than those receiving CRT-P for primary prevention. However, after adjustment for covariates, the better outcomes in patients with CRT-D vs. CRT-P were no longer significant. CRT-P recipients were less likely to be taking medications such as $\beta$-blockers, ACEI/ARB, and aldosterone antagonists than CRT-D recipients in the JCDTR.

The efficacy of ICD implantation for primary prevention of sudden cardiac death has been conclusively demonstrated in patients with prior myocardial infarction and reduced $\mathrm{LVEF}\left(\leq 35 \% 0^{\mathbf{1 1}}\right.$ or $\left.\leq 30 \%{ }^{\mathbf{1 2}}\right)$, whereas reports regarding its efficacy in non-ischemic cardiomyopathy are conflicting. ${ }^{13-16}$ Men were more likely to experience ventricular tachyarrhythmia episodes than women among patients with coronary artery disease and an ICD ${ }^{17}$ In agreement, the benefits of ICD in heart failure patients with CRT were reported to be greater for patients with an ischemic etiology of cardiomyopathy and in males. ${ }^{18-20}$ In addition, patients with low (0-2) Goldenberg risk scores, which would indicate less comorbidity and a younger age, appeared to receive a substantial benefit from a defibrillator. ${ }^{21}$ In a retrospective observational study, CRT-D recipients aged $\geq 75$ years did not have lower mortality than CRT-P recipients after adjusting for possible confounders. ${ }^{22}$ Further studies are required to determine which patients with no prior sustained ventricular tachyarrhythmias will benefit from a defibrillator in CRT, and there may be a need for randomized studies, especially in non-ischemic cardiomyopathy, to elucidate optimal CRT device selection.

In the COMPANION study, ${ }^{2}$ CRT-D implantation was associated with a $36 \%$ reduction in the risk of death from any cause (hazard ratio $0.64 ; 95 \%$ CI $0.48-0.86 ; \mathrm{P}=0.003$ ) compared with pharmacologic therapy, whereas CRT-P implantation was associated with a marginally significant reduction $(24 \%)$ in risk (hazard ratio 0.76 ; $95 \%$ CI 0.58 $1.01 ; \mathrm{P}=0.059)$. This indicated the superiority of CRT-D over CRT-P in terms of the mortality benefit, but the magnitude of this benefit appeared to be small.

The present study did not demonstrate a significant reduction in risk of death with CRT-D over CRT-P. There could be several reasons that explain this observation. First, the mean follow-up duration of 21 months was relatively short. A review of controlled trials suggested that some of the superior effects of CRT-D over CRT-P, such as on all-cause mortality, manifested after a longer followup period (i.e., >1 year). ${ }^{23}$ Second, the proportion of patients with a history of NSVT in the present study was higher in the CRT-D than CRT-P group, and we were not able to adjusted for this difference. A subanalysis of Sudden Cardiac Death in Heart Failure Trial (SCD-HeFT) reported that rapid NSVTs indicated a 4.3-fold increase in the risk of appropriate ICD shocks in patients with mild-to-moderate heart failure and LVEF of $\leq 35 \% .{ }^{24}$ Furthermore, the presence of rapid NSVTs was independently associated with all-cause mortality. ${ }^{24}$ Third, non-ischemic etiology was prevalent, especially in patients receiving CRT-P, in the present study, although it was not statistically significant (Table 1). The DANISH trial (Danish Study to Assess the Efficacy of ICDs in Patients with Non-ischemic Systolic Heart Failure on Mortality) demonstrated that the addition of ICD function fails to prolong survival in symptomatic heart failure patients with non-ischemic cardiomyopathy who have an LVEF of $\leq 35 \% .{ }^{15}$ Recently, in an observational cohort study in Europe, non-ischemic patients with indications for CRT did not benefit from additional primary prevention ICD therapy, as opposed to ischemic patients. $^{25}$ This may be related to the facts that: (1) CRT offers a more favorable response with regard to reverse LV remodeling in cases of non-ischemic cardiomyopathy; and (2) the substrate for ventricular arrhythmias in ischemic cardiomyopathy appears to be more severe compared with a non-ischemic etiology. ${ }^{26}$

Although the effect of CRT on heart failure would be the same in both groups, a composite endpoint of death or heart failure hospitalization was reduced in the CRT-D compared with CRT-P group. This may be because: (1) the proportion of patients receiving $\beta$-blockers and aldosterone antagonists was significantly lower in the CRT-P than CRT-D group (Table 2); and (2) CRT-P recipients had more comorbidities, as determined using the Goldenberg risk score (Table 1). More intensive medical therapy with $\beta$-blockers, ${ }^{27-29}$ ACEI/ARB, ${ }^{30-33}$ and aldosterone antagonists ${ }^{34,35}$ may have improved outcomes of death or heart failure hospitalization in patients receiving CRT-P. In 
addition, patients with CRT-D are likely to be under remote monitoring because of a defibrillator. In a randomized control study, ${ }^{\mathbf{3 6}}$ as well as in observational studies, $, 37,38$ remote monitoring was associated with a lower rate of hospital admission for heart failure or all-cause mortality.

The rate of sudden cardiac death tended to be lower in the CRT-D than CRT-P group, but the difference between the 2 groups did not reach statistical significance. This appears to be due to the low proportion of sudden cardiac deaths in heart failure patients treated with guidelinedetermined medical therapy and CRT. For example, the rate of sudden cardiac death was $1.18 \%$ and $1.08 \%$ per patient years in CRT-P recipients in the Certitude cohort ${ }^{39}$ and REVERSE ${ }^{4}$ studies, respectively. In these studies, the incidence of sudden cardiac death was not significantly higher in the CRT-P compared with CRT-D group. Moreover, first ICD shock efficacy in the MADIT-CRT study was approximately $90 \%, 40$ and the rate of successful conversion of spontaneous ventricular arrhythmias at the final ICD therapy was reported to be $97.3 \% .41$ Such failed ICD therapies may be due to the presence of patients with a high defibrillation threshold, ${ }^{42}$ undersensing of ventricular fibrillation, ${ }^{43}$ and device malfunction. ${ }^{43}$ In addition, Holter electrocardiogram (ECG) monitoring revealed that approximately $20 \%$ of patients had bradyarrhythmias during sudden cardiac death, ${ }^{\mathbf{4 4 , 4 5}}$ and some of these could be pulseless electrical activity. In fact, the rate of sudden cardiac death in the CRT-D group in the COMPANION study was $2.9 \%$ during the 15.7 -month follow-up period ${ }^{46}$ which is comparable to the $2.7 \%$ rate at 2 years in the present study (Figure 2D).

The results of the preset study suggest that there are 2 subgroups that will gain a larger benefit from a defibrillator: (1) patients with a reduced LVEF ( $\leq 30 \%)$; and (2) patients with NSVT (Figure 3). Conversely, care should be taken when interpreting the results based on unadjusted analyses. In addition, data concerning the history of NSVT was missing for $60 \%(n=433)$ of patients (Table 1). This shortcoming is related to the data entry system of the JCDTR, where entering information as to the presence or absence of NSVT is not mandatory to finish registration.

\section{Study Limitations}

There are several limitations to be considered in the present study. First, the JCDTR database relies on voluntary efforts of members of the JHRS, and would not include all data for consecutive patients in each hospital. However, more than 378 facilities across Japan have contributed to the registry, which means that the data could be representative of the outcomes of patients with CRT in Japan. Second, although the present study presented outcomes of patients who underwent CRT-D $(n=620)$ or CRT-P $(n=97)$ implantation for primary prevention from the entire cohort (2714 CRT-D, 555 CRT-P) reported previously, ${ }^{9}$ the number of patients in the 2 groups in the present study suggests that follow-up data are not easily obtained from the JCDTR, being available for only $23 \%$ of the CRT-D group and $17 \%$ of the CRT-P group. Conversely, the characteristics of the patients in the present study (Tables 1,2) were almost identical to those reported in the previous study. ${ }^{9}$ Third, the number of patients (especially CRT-P recipients) was relatively small for adjusting large differences in the background and medications of the 2 study groups (CRT-D vs. CRT-P). Fourth, the present study was limited by a lack of important data, such as the rate of responders and the morphology of the original QRS complex (left bundle block or right bundle block). In general, the effect of CRT was equal in both groups.

\section{Conclusions}

The present study demonstrated that patients with CRT-D for primary prevention enrolled in the JCDTR had a lower rate of death or heart failure hospitalization during a mean follow-up of 21 months than patients with CRT-P. There was a tendency for lower rates of death from any cause, death or heart failure hospitalization, heart failure death, and sudden cardiac death, in patients with CRT-D compared with CRT-P, although the differences failed to reach statistical significance.

\section{Acknowledgments}

The authors thank all the members of the JHRS who registered data in the JCDTR on a voluntary basis. As of 13 January 2017, 378 facilities in Japan had enrolled at least 1 patient. A list of the 97 facilities that have enrolled more than 100 patients in the JCDTR is provided in the Appendix.

\section{Conflicts of Interest}

All authors declare no conflicts of interest related to this study.

\section{References}

1. Abraham WT, Fisher WG, Smith AL, Delurgio DB, Leon AR, Loh E, et al. Cardiac resynchronization in chronic heart failure. $N$ Engl J Med 2002; 346: 1845-1853.

2. Bristow MR, Saxon LA, Boehmer J, Krueger S, Kass DA, De Marco T, et al. Cardiac-resynchronization therapy with or without an implantable defibrillator in advanced chronic heart failure. N Engl J Med 2004; 350: 2140-2150.

3. Cleland JG, Daubert JC, Erdmann E, Freemantle N, Gras D, Kappenberger L, et al. The effect of cardiac resynchronization on morbidity and mortality in heart failure. $N$ Engl J Med 2005; 352: $1539-1549$.

4. Gold MR, Daubert JC, Abraham WT, Hassager C, Dinerman $\mathrm{JL}$, Hudnall JH, et al. Implantable defibrillators improve survival in patients with mildly symptomatic heart failure receiving cardiac resynchronization therapy: Analysis of the long-term follow-up of remodeling in systolic left ventricular dysfunction (reverse). Circ Arrhythm Electrophysiol 2013; 6: 1163-1168.

5. Schuchert A, Muto C, Maounis T, Frank R, Boulogne E, Polauck A, et al. Lead complications, device infections, and clinical outcomes in the first year after implantation of cardiac resynchronization therapy-defibrillator and cardiac resynchronization therapy-pacemaker. Europace 2013; 15: 71-76.

6. Shimizu A, Mitsuhashi T, Furushima H, Sekiguchi Y, Manaka $\mathrm{T}$, Nishii $\mathrm{N}$, et al. Current status of cardiac resynchronization therapy with defibrillators and factors influencing its prognosis in Japan. J Arrhythm 2013; 29: 168-174.

7. Shimizu A, Nitta T, Kurita T, Imai K, Kimura T, Kobayashi Y, et al. Current status of implantable defibrillator devices in patients with left ventricular dysfunction: The first report from the online registry database. J Arrhythm 2008; 24: 133-140.

8. Shimizu A, Nitta T, Kurita T, Imai K, Kobayashi Y, Soejima K, et al. Actual conditions of implantable defibrillator therapy over 5 years in Japan. J Arrhythm 2012; 28: 263-272.

9. Yokoshiki H, Shimizu A, Mitsuhashi T, Furushima H, Sekiguchi $Y$, Manaka T, et al. Trends and determinant factors in the use of cardiac resynchronization therapy devices in Japan: Analysis of the Japan Cardiac Device Treatment Registry database. $J$ Arrhythm 2016; 32: 486-490.

10. Goldenberg I, Vyas AK, Hall WJ, Moss AJ, Wang H, He H, et al. Risk stratification for primary implantation of a cardioverterdefibrillator in patients with ischemic left ventricular dysfunction. J Am Coll Cardiol 2008; 51: 288-296.

11. Moss AJ, Hall WJ, Cannom DS, Daubert JP, Higgins SL, Klein $\mathrm{H}$, et al. Improved survival with an implanted defibrillator in patients with coronary disease at high risk for ventricular arrhythmia: Multicenter Automatic Defibrillator Implantation Trial Investigators. N Engl J Med 1996; 335: 1933-1940. 
12. Moss AJ, Zareba W, Hall WJ, Klein H, Wilber DJ, Cannom DS, et al. Prophylactic implantation of a defibrillator in patients with myocardial infarction and reduced ejection fraction. $N$ Engl $J$ Med 2002; 346: 877-883.

13. Bansch D, Antz M, Boczor S, Volkmer M, Tebbenjohanns J, Seidl K, et al. Primary prevention of sudden cardiac death in idiopathic dilated cardiomyopathy: The Cardiomyopathy Trial (CAT). Circulation 2002; 105: 1453-1458.

14. Kadish A, Dyer A, Daubert JP, Quigg R, Estes NA, Anderson $\mathrm{KP}$, et al. Prophylactic defibrillator implantation in patients with nonischemic dilated cardiomyopathy. N Engl J Med 2004; 350: $2151-2158$.

15. Kober L, Thune JJ, Nielsen JC, Haarbo J, Videbaek L, Korup E, et al. Defibrillator implantation in patients with nonischemic systolic heart failure. $N$ Engl J Med 2016; 375: 1221-1230.

16. Strickberger SA, Hummel JD, Bartlett TG, Frumin HI, Schuger $\mathrm{CD}$, Beau SL, et al. Amiodarone versus implantable cardioverter-defibrillator: Randomized trial in patients with nonischemic dilated cardiomyopathy and asymptomatic nonsustained ventricular tachycardia - AMIOVIRT. J Am Coll Cardiol 2003; 41: $1707-1712$

17. Lampert R, McPherson CA, Clancy JF, Caulin-Glaser TL, Rosenfeld LE, Batsford WP. Gender differences in ventricular arrhythmia recurrence in patients with coronary artery disease and implantable cardioverter-defibrillators. J Am Coll Cardiol 2004; 43: 2293-2299.

18. Barra S, Providencia R, Tang A, Heck P, Virdee M, Agarwal S. Importance of implantable cardioverter-defibrillator back-up in cardiac resynchronization therapy recipients: A systematic review and meta-analysis. J Am Heart Assoc 2015; 4: e002539.

19. Kutyifa V, Geller L, Bogyi P, Zima E, Aktas MK, Ozcan EE, et al. Effect of cardiac resynchronization therapy with implantable cardioverter defibrillator versus cardiac resynchronization therapy with pacemaker on mortality in heart failure patients: Results of a high-volume, single-centre experience. European J Heart Fail 2014; 16: $1323-1330$.

20. Witt CT, Kronborg MB, Nohr EA, Mortensen PT, Gerdes C, Jensen HK, et al. Adding the implantable cardioverter-defibrillator to cardiac resynchronization therapy is associated with improved long-term survival in ischaemic, but not in non-ischaemic cardiomyopathy. Europace 2016; 18: 413-419.

21. Barra S, Looi KL, Gajendragadkar PR, Khan FZ, Virdee M, Agarwal S. Applicability of a risk score for prediction of the long-term benefit of the implantable cardioverter defibrillator in patients receiving cardiac resynchronization therapy. Europace 2016; 18: 1187-1193.

22. Munir MB, Althouse AD, Rijal S, Shah MB, Abu Daya H, Adelstein E, et al. Clinical characteristics and outcomes of older cardiac resynchronization therapy recipients using a pacemaker versus a defibrillator. J Cardiovasc Electrophysiol 2016; 27: 730 734.

23. Jiang M, He B, Zhang Q. Comparison of CRT and CRT-D in heart failure: Systematic review of controlled trials. Int J Cardiol 2012; 158: $39-45$.

24. Chen J, Johnson G, Hellkamp AS, Anderson J, Mark DB, Lee KL, et al. Rapid-rate nonsustained ventricular tachycardia found on implantable cardioverter-defibrillator interrogation: Relationship to outcomes in the SCD-HEFT (Sudden Cardiac Death In Heart Failure Trial). J Am Coll Cardiol 2013; 61: 2161-2168.

25. Barra S, Boveda S, Providencia R, Sadoul N, Duehmke R, Reitan C, et al. Adding defibrillation therapy to cardiac resynchronization on the basis of the myocardial substrate. J Am Coll Cardiol 2017; 69: 1669-1678.

26. Yokoshiki H, Mitsuyama H, Watanabe M, Mitsuhashi T, Shimizu A. Cardiac resynchronization therapy in ischemic and non-ischemic cardiomyopathy. J Arrhythm, doi:10.1016/j.joa.2017.03.002.

27. Effect of metoprolol $\mathrm{cr} / \mathrm{xl}$ in chronic heart failure: Metoprolol $\mathrm{CR} / \mathrm{XL}$ Randomised Intervention Trial in Congestive Heart Failure (MERIT-HF). Lancet 1999; 353: 2001-2007.

28. The Cardiac Insufficiency Bisoprolol Study II (CIBIS-II): A randomised trial. Lancet 1999; 353: 9-13.

29. Packer M, Bristow MR, Cohn JN, Colucci WS, Fowler MB, Gilbert EM, et al. The effect of carvedilol on morbidity and mortality in patients with chronic heart failure: U.S. Carvedilol Heart Failure Study Group. N Engl J Med 1996; 334: 1349-1355.

30. CONSENSUS Trial Study Group. Effects of enalapril on mortality in severe congestive heart failure: Results of the Cooperative North Scandinavian Enalapril Survival Study (Consensus). $N$ Engl J Med 1987; 316: 1429-1435.

31. SOLVD Investigators, Yusuf S, Pitt B, Davis CE, Hood WB,
Cohn JN. Effect of enalapril on survival in patients with reduced left ventricular ejection fractions and congestive heart failure. $N$ Engl J Med 1991; 325: 293-302.

32. Granger CB, McMurray JJ, Yusuf S, Held P, Michelson EL, Olofsson B, et al. Effects of candesartan in patients with chronic heart failure and reduced left-ventricular systolic function intolerant to angiotensin-converting-enzyme inhibitors: The CHARM-Alternative trial. Lancet 2003; 362: 772-776.

33. McMurray JJ, Ostergren J, Swedberg K, Granger CB, Held P, Michelson EL, et al. Effects of candesartan in patients with chronic heart failure and reduced left-ventricular systolic function taking angiotensin-converting-enzyme inhibitors: The CHARM-Added trial. Lancet 2003; 362: 767-771.

34. Pitt B, Remme W, Zannad F, Neaton J, Martinez F, Roniker B, et al. Eplerenone, a selective aldosterone blocker, in patients with left ventricular dysfunction after myocardial infarction. $N$ Engl J Med 2003; 348: 1309-1321.

35. Pitt B, Zannad F, Remme WJ, Cody R, Castaigne A, Perez A, et al. The effect of spironolactone on morbidity and mortality in patients with severe heart failure: Randomized aldactone evaluation study investigators. N Engl J Med 1999; 341: 709-717.

36. Hindricks G, Taborsky M, Glikson M, Heinrich U, Schumacher B, Katz A, et al. Implant-based multiparameter telemonitoring of patients with heart failure (in-time): A randomised controlled trial. Lancet 2014; 384: 583-590.

37. De Simone A, Leoni L, Luzi M, Amellone C, Stabile G, La Rocca V, et al. Remote monitoring improves outcome after ICD implantation: The clinical efficacy in the management of heart failure (EFFECT) study. Europace 2015; 17: 1267-1275.

38. Saxon LA, Hayes DL, Gilliam FR, Heidenreich PA, Day J, Seth $\mathrm{M}$, et al. Long-term outcome after ICD and CRT implantation and influence of remote device follow-up: The ALTITUDE survival study. Circulation 2010; 122: 2359-2367.

39. Marijon E, Leclercq C, Narayanan K, Boveda S, Klug D, Lacaze-Gadonneix J, et al. Causes-of-death analysis of patients with cardiac resynchronization therapy: An analysis of the CeRtiTuDe cohort study. Eur Heart J 2015; 36: 2767-2776.

40. Kutyifa V, Huth Ruwald AC, Aktas MK, Jons C, McNitt S, Polonsky B, et al. Clinical impact, safety, and efficacy of singleversus dual-coil ICD leads in MADIT-CRT. $J$ Cardiovasc Electrophysiol 2013; 24: 1246-1252.

41. Gold MR, Higgins S, Klein R, Gilliam FR, Kopelman H, Hessen $\mathrm{S}$, et al. Efficacy and temporal stability of reduced safety margins for ventricular defibrillation: Primary results from the low energy safety study (LESS). Circulation 2002; 105: 2043-2048.

42. Mizukami K, Yokoshiki H, Mitsuyama H, Watanabe M, Tenma T, Matsui Y, et al. Predictors of high defibrillation threshold in patients with implantable cardioverter-defibillator using a transvenous dual-coil lead. Circ J 2015; 79: 77-84.

43. Tseng ZH, Hayward RM, Clark NM, Mulvanny CG, Colburn BJ, Ursell PC, et al. Sudden death in patients with cardiac implantable electronic devices. JAMA Intern Med 2015; 175: $1342-1350$.

44. Bayes de Luna A, Coumel P, Leclercq JF. Ambulatory sudden cardiac death: Mechanisms of production of fatal arrhythmia on the basis of data from 157 cases. Am Heart J 1989; 117: 151-159.

45. Watanabe E, Tanabe T, Osaka M, Chishaki A, Takase B, Niwano S, et al. Sudden cardiac arrest recorded during holter monitoring: Prevalence, antecedent electrical events, and outcomes. Heart Rhythm 2014; 11: 1418-1425.

46. Carson P, Anand I, O'Connor C, Jaski B, Steinberg J, Lwin A, et al. Mode of death in advanced heart failure: The comparison of medical, pacing, and defibrillation therapies in heart failure (COMPANION) trial. J Am Coll Cardiol 2005; 46: 2329-2334.

\section{Appendix}

Facilities (in alphabetical order) that have enrolled more than 100 patients in the JCDTR as of 13 January 2017:

Akita Medical Center; Anjo Kosei Hospital; Dokkyo Medical University; Edogawa Hospital; Fujita Health University; Fukushima Medical University; Gifu University; Gunma University; Hirosaki University; Hokkaido University Hospital; Hokko Memorial Hospital; Hyogo College of Medicine; IMS Katsushika Heart Center; Ishinomaki Red Cross Hospital; Itabashi Chuo Medical Center; Japanese Red Cross Society Kyoto Daini Hospital; Japanese Red Cross Wakayama Medical Center; JCHO Hokkaido Hospital; JCHO Kyushu Hospital; Jichi Medical University; Juntendo University; Juntendo University Urayasu Hospital; Kakogawa East City Hospital; Kameda Medical Center; Kanazawa Medical University; Keio University; Kitasato 
University; Kochi Health Science Center; Kokura Memorial Hospital; Komaki City Hospital; Kumamoto Red Cross Hospital; Kumamoto University; Kurashiki Chuo Hospital; Kyorin University; Kyoto Prefectural University of Medicine; Kyoto-Katsura Hospital; Maebashi Red Cross Hospital; Matsudo City Hospital; Matsue Red Cross Hospital; Matsumoto Kyoritsu Hospital; Mie University; Mito Saiseikai General Hospital; Nagasaki University; Nagoya University; Nara Medical University; National Hospital Organization Kagoshima Medical Center; National Hospital Organization Shizuoka Medical Center; Nihon University; Niigata University; Nippon Medical School Chiba Hokusou Hospital; Nippon Medical University; Odawara Municipal Hospital; Okayama University; Okinawa Prefectural Chubu Hospital; Osaka City General Hospital; Osaka City University; Osaka Medical College; Osaka Police Hospital; Osaka Red Cross Hospital; Osaka University; Saiseikai Fukuoka General Hospital; Saiseikai Kumamoto Hospital; Saiseikai Shimonoseki General Hospital; Saiseikai Yokohamashi Tobu Hospital; Saitama Red Cross Hospital; Sakurabashi Watanabe Hospital; Seirei Hamamatsu General Hospital; Sendai Kosei Hospital; Shiga University of Medical Science; Shinshu University; Shizuoka municipal Hospital; Showa General Hospital; St. Luke's International Hospital; St. Marianna University School of Medicine; Takeda Hospital; Tenri Hospital; The
University of Tokyo; Toho University; Tokai University; Tokyo Medical University; Tokyo Metropolitan Hiroo Hospital; Tokyo Metropolitan Tama Medical Center; Tokyo Women's Medical University; Tottori University; Toyama Prefectural Central Hospital; Toyohashi Heart Center; Tsuchiura Kyodo General Hospital; Tsukuba Medical Center Hospital; University of Fukui; University of Miyazaki; University of Occupational and Environmental Health; University of Tsukuba; Yamagata Prefectural Central Hospital; Yamagata University; Yamaguchi University; Yamanashi Prefectural Central Hospital; Yokohama Rosai Hospital.

\section{Supplementary Files}

\section{Supplementary File 1}

Table S1. Characteristics and pharmacological therapy in 4 CRT-P recipients experiencing sudden cardiac death

Table S2. Patient characteristics and pharmacological therapy after propensity score matching

Please find supplementary file(s); http://dx.doi.org/10.1253/circj.CJ-17-0234 